\title{
ERRATUM
}

\section{Coordinated gripping of substrate by subunits of an AAA+ proteolytic machine}

Ohad Iosefson, Andrew R Nager, Tania A Baker \& Robert T Sauer

Nat. Chem. Biol.; doi:10.1038/nchembio.1732; published online 19 January 2015; corrected before print 30 January 2015

There was a mismatch between the PDF and the HTML versions upon online release. In addition, the title of the article and the third sentence of the article have been modified by changing 'an' to 'a' before AAA+. The first sentence of the first paragraph was edited incorrectly and has been modified to reflect the correct meaning. Finally, in the last sentence on page 5, the word 'given' has been modified to 'based on'. These errors have been corrected in the HTML and PDF versions of the article.

\section{ERRATUM}

\section{Chemical biologists rush to San Francisco for the ICBS}

Evan W Miller

Nat. Chem. Biol. 11, 91-95 (2015); published online 20 January 2015; corrected after print 24 February 2015

In the version of this article initially printed, the page numbers for reference 2 were incorrect. The page numbers are correct in the HTML and PDF versions of the article.

\section{CORRIGENDUM}

\section{Chemical biologists rush to San Francisco for the ICBS}

Evan W Miller

Nat. Chem. Biol. 11, 91-95 (2015); published online 20 January 2015; corrected after print 24 February 2015

In the version of this article initially published, Jie Li's name was misspelled. The error has been corrected in the HTML and PDF versions of the article.

\section{CORRIGENDUM}

\section{Arginine-rhamnosylation as new strategy to activate translation elongation factor $\mathrm{P}$}

Jürgen Lassak, Eva C Keilhauer, Maximilian Fürst, Kristin Wuichet, Julia Gödeke, Agata L Starosta, Jhong-Min Chen, Lotte Søgaard-Andersen, Jürgen Rohr, Daniel N Wilson, Susanne Häussler, Matthias Mann \& Kirsten Jung

Nat. Chem. Biol.; doi:10.1038/nchembio.1751; corrected online 24 February 2015

In the version of this article initially published online, the second author's middle initial was inadvertently omitted. The error has been corrected for the print, PDF and HTML versions of this article. 